\title{
Needs Analysis English For Specific Purposes (ESP) For Vocational Pharmacy Students
}

\author{
Abd. Syakur', H.M Zainuddin'2, M. Afif Hasan ${ }^{3}$ \\ ${ }^{1}$ Postgraduate Program of English Education, STKIP PGRI Sidoarjo, Indonesia \\ ${ }^{2}$ Postgraduate Program of Social and science, Universitas Negeri Malang, Indonesia \\ ${ }^{3}$ Postgraduate Programs Pedagogical Educations, INSTIKA, Indonesia \\ syakurabdmpd@gmail.com
}

\begin{abstract}
Increased creation of academic programmes in vocational education programs, which is expected to be a solution for increasing Indonesia's human capital. This also underpins Indonesia's efforts to develop English language proficiency, as illustrated in Minister of Education and Culture. The Ministry of Education and Culture helped English vocational education students who required assistance with listening, reading, writing, and speaking improve their communicative skills. This study examines the needs of English courses (ESP) for educational students who need target and learning needs review. Questionnaires and interviews were used to collect data. The effects of data research on active communication skills (35\%), grammar difficulties (25\%), reading ability (25\%), material difficulty (10\%), ability (25\%) and writing ( $5 \%)$. Basic pharmacy (20\%), prescription pharmacy (20\%), health and medications (20\%), healthy lifestyle (20\%), and microbiology and pharmacy (20\%) are the topics covered (20 percent). English Media (40\%) is the most commonly used English language in technology, followed by crosswords (20\%), dialogue content (20\%), and multiple choice (20\%). The study's findings are an overview of the needs and goals associated with the English learning process. The findings of a study of students' academic needs and their progress in learning English, including reading, writing, grammar, and other skills, in order to better prepare them to meet their future needs.
\end{abstract}

Keywords

Learning needs, needs analysis, speaking competency

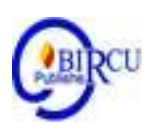

\section{Introduction}

The spread of English is now increasingly widespread and continues so that people in developing countries including Indonesia (Antony et al., 2015). Currently English has an increasingly dominant influence and role in several parts of the world. In fact, various information about world science and technology is mostly delivered in English (Ma et al., 2015). Global communication relies heavily on English language skills because English has become a means to access valuable information and resources delivered through various media, both print and electronic media in accordance with SDGs and MDGs found in Education for Sustainable Development (ESD) (Hermann et al., 2016). This is a response from the Issues of Global Challenges through Character Education and National Insight. 
Indonesian people are increasingly aware of the importance of having English language skills, both oral and written abilities. Therefore, the Indonesian government decided the policy that English was the first foreign language taught in vocational education in diploma three (D3) departments of pharmacy (Aysan, 2015), starting from elementary school level to university level. The Indonesian government also allows the use of English as the language of instruction in the world of education. Even some leading vocational schools and colleges in big cities in various regions in Indonesia present a plus with a semi-international program (Budiarta and Krismayani, 2014, Aysan, 2015). Through the use of English as the language of instruction in vocational colleges as well as at the Academy, Polytechnic and Poltekes levels.

The purpose of teaching English in Indonesia has been stated in Minister of Education and Culture Decree No. 096/1967 dated 12 December 1967, Especially, increasing English vocational education students' communicative abilities, which included listening, reading, writing, and speaking abilities. At the tertiary level, students are expected to already have knowledge of English grammar and can then apply that knowledge in communicating and interacting in real life (Budiarta and Krismayani, 2014).

Studying English is an important asset for vocational education students to answer various challenges in their professional world. Of course, the lecturer's position is critical in assisting students in developing adequate English language skills. Students of vocational education were instructed by English lecturers (English for Specific Purposes) (Ottolini et al., 2010). They are asked to develop a Semester Program Plan (RPS) and Learning Implementation Plan (RPP) and develop teaching materials based on the needs of students. They must meet students' real-world professional demands effectively. However, the problems that occur in Indonesia, particularly in diploma three (D3) pharmacy department of Surabaya Pharmacy Academy, many English lecturers who teach in the field of vocational education, namely diploma three who have difficulty in designing Semester Program Plans (RPS) and Learning Implementation Plans (RPP) and teaching materials for diploma three (D3) pharmacy department of Surabaya Pharmacy Academy. Teaching English at the Surabaya Pharmacy Academy, for example, is difficult since special English books for vocational education students are unavailable at the local bookstore, making it difficult for lecturers to design teaching materials. As a result, analyzing the needs of students would be a viable answer to the issue at hand.

Based on the above literature, needs analysis plays an important role in teaching because through needs analysis, lecturers / teachers, students, teaching materials, teaching procedures; all can be connected in harmony to improve the learning process of students (Wats and Wats, 2009, Robles, 2012, Shahroom and Hussin, 2018). Because of that researchers are motivated to conduct an analysis of the needs of English courses for students of D3 departments of Pharmacy Academy of Pharmacy Surabaya. This research is the first stage of a series of future studies in the process of developing and evaluating teaching material in English vocational education courses. The initial emphasis in designing and creating instructional materials will be on analyzing student needs. This study is necessary in order to assist lecturers in developing instructional materials, as well as to assist vocational education students in gaining access to the unique language they need in order to interact effectively in light of the demands of their workplace. The resulting formulation is intended to be used to compile and improve instructional material and instructional methods (both in the form of teaching modules, techniques, applications, and others) to aid teachers / lecturers in teaching and learning in the classroom in the future. 


\section{Review of Literature}

\subsection{Need Analysis}

When we talk about needs analysis it cannot be separated from the development of material and curriculum or what is known as Curriculum and Material Development (Lindsey et al., 2003, Manis et al., 2004,Wats and Wats, 2009). The process of developing material is a central element in language programs. The process of material development according to (Antony et al., 2015) includes:

\section{a. Need Analysis}

The process of collecting knowledge about students' needs is known as needs analysis. Robles (2012) shared the same viewpoint, stating that the needs analysis procedure was used to collect knowledge about students' needs. The author compiles a needs analysis instrument in the form of a questionnaire taken from (Robles, 2012).

(1) Overview of skills needed and difficulties encountered.

(2) Overview of topics needed,

(3) Communicative Competence Components: Skills (listening, speaking, reading, writing), linguistics competence (grammar, vocabulary, pronunciations, punctuation, stress and spelling), Socio-culture and communication strategy.

\section{b. Formulating Goals}

Formulating objectives is an important dimension of decision making in the design of the Semester Program Plan (RPS) and Learning Implementation Plan (RPP). Here the author concludes that the intended purpose is written in Basic Competence (BC) and Competency Standards (CS). Some explanations about the learning objectives according to (Robles, 2012) as follows:

(1) The purpose is usually a general statement

(2) Generally motivational statements to achieve certain goals.

(3) A program will be effective if the objectives are clearly described.

\section{c. Organizing the course content}

The preparation of the material is as follows:

(1) Observing that Standards Competency must be in accordance with Basic Competencies.

(2) Developing material.

(3) Organize learning activities.

(4) Determine indicators,

(5) Determine evaluation,

(6) Determine the time,

(7) State the source.

\section{d. English for Specific Purposes}

Before going into detail about English for Specific Purposes, the author wants to explain what ESP is. According to http://cborba.tripod.com/ESPoli.htm, ESP is a language teaching methodology in which material and approaches are focused on the students' motives for learning. As a result, ESP is focusing on making English classes more important to students' needs. As a result, ESP stands for basic learning. English for Pharmacy is a teaching method that aims to help students achieve their goals or competencies in mastering English in the field of medicine or pharmacy. 


\section{e. Teaching Learning Process in ESP}

Evans and John stated that teaching ESP is different from EFL teaching (Soliman, 2014). This arises mainly from two factors related to students: the specialist knowledge they carry - both conscious and latent and from the cognitive and learning processes that they bring from learning and working experiences in their specialist fields. One reason for the reasonableness of these two factors concerns the type of activity through which learning takes place. In addition to language learning activities, ESP classrooms use assignments and activities that reflect the world of specialist students. Furthermore, they explained that the skill needed by ESP lecturers was the ability to assess a situation from various points of view and then choose and adapt their methodology to suit the needs of students. Flexibility and willingness to take risks is the name of the rule.

\section{f. Need Assessment}

Requirements assessment is needed for ESP lecturers to prepare their Semester Program Plans (RPS) and Learning Implementation Plans (RPPs) and provide appropriate instructional material. A needs analysis is carried out to establish what and how the course is the first phase of ESP development followed by curriculum design, material selection, methodology, assessment and evaluation. The needs analysis includes two things: first, students' personal information which includes factors that influence the way they learn such as prior learning experiences, cultural information, reasons for attending courses and their attitude towards English. Second, information on the language teaching environment such as human resources and administrative issues.

\section{g. Higher Education Curriculum}

Curriculum is a term that refers to a program that is developed and implemented in order to accomplish educational goals. The program can be viewed as a blueprint for constructing a home. The focus is on the future. As a result, curriculum milestones are critical to meeting program objectives.

As we are aware, the Indonesian Ministry of Education and Culture is currently revising its curricula. Changes in Competency Based Curriculum towards KKNI-based Curriculum (Indonesian National Qualification Framework). In the KKNI curriculum, competencies are expected to be able to juxtapose, equalize, and integrate (from the level of vocational education to S3) between the field of education and the field of job training and work experience in order to provide recognition of work competence in accordance with the organizational structure of the Ministry of Education and Culture's various sectors.

The curriculum is designed to level the playing field for graduates so they can compete in the employment market. According to the Ministry of Education and Culture (2011), the competencies required for level 5 of the D3 Program are as follows: (1) Capable of applying their expertise and utilizing science and technology in their fields to solve problems and adapt to the situation at hand. (2) Acquiring a thorough understanding of the theoretical concepts underlying a particular field of knowledge in general, as well as the theoretical concepts underlying specific sections within that field of knowledge, as well as the ability to formulate procedural problem solving.

From the explanation above, students are expected to be able to master the concepts theoretically in their field of knowledge. However, based on observations made by the author, that the aforementioned tertiary institutions have not made changes and developed curriculum based on KKNI. So they still use the old curriculum which is competency-based curriculum. In the competency-based curriculum English courses are general subjects that are mandatory for all students. At least taken in two semesters with a total of four credits. 


\section{Research Method}

This research is research related to the type of learning needed and the instructional approach that best suits these needs, the authors tend to use the method of research development (Research \& Development). (Mayfield, 2011) sets the definition into the realm of education by defining this type of research as a systematic study to develop and evaluate processes with the aim of establishing an empirical basis for the creation of instructional and non-instructional products. Stages and procedures in conducting this research will use Dick, Carey \& Carey's (1990) Instructional Development Model. The steps will be implemented in ADDIE (Analysis, Design, Development, Implementation, and Evaluation) activities. Because this research is the initial stage of the five steps above, the research that will be carried out is a needs analysis.

The subjects in this study were the first semester students of diploma three (D3) pharmacy department of Surabaya Pharmacy Academy in academic year 2018/2019. Research data were obtained using questionnaires and structured interviews with lecturers and students about their learning needs. The results of the study are reported in the form of descriptive statistics, namely by displaying statistical data and an explanation of these data.

\section{Discussion}

In the results of this research discussion that the data processing in this study was carried out by processing data based on English courses for students of diploma three (D3) pharmacy department of Surabaya Pharmacy Academy which is a compulsory subject that must be taught by every student in the first and second semester. Like English lectures in other majors, English lectures in diploma three (D3) pharmacy department of Surabaya Pharmacy Academy are held once a week with a number of students around 40-42 students. Based on a survey of students' English proficiency, $70 \%$ of students are beginners and 30\% of them are at an advanced level. Most of them are still at the beginner level because they almost never use English in their daily conversation even though they have been studying English since elementary school for years.

Based on the survey conducted (Images 1), the first question asks about the purpose of students learning English. The most common answer is to be able to actively communicate with regard to health issues and terms in pharmacy. This shows that students feel they need English language skills because in the future they will face their career needs that demand fluency in communicating in English. The second most answer is so that they are able to understand the grammar found in English both in reading and in conversation. When they are proficient in the use of grammar, then this can facilitate them in speaking, understanding reading and writing. The same percentage of answers are at point two, namely to be able to understand books, journals, readings, and reports in the health and pharmaceutical fields in English; and the fourth point is able to understand the contents of the conversation, speech / lecture, and reputation that is heard in English. The least answer is to be able to write or make a report or article in English related to health and pharmacy. The percentage in diagram form is as follows (Figure 1): 


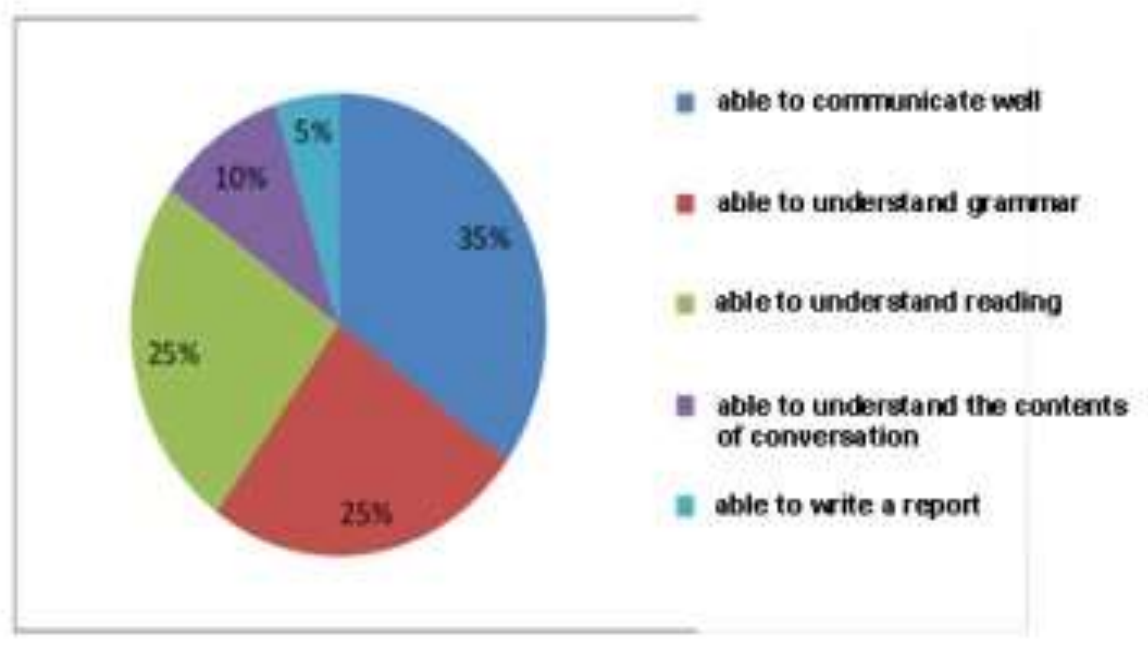

Figure 1. Purpose of Students Studying English (ESP)

In connection with the picture above, the most answers to questions about abilities or skills that are considered important in learning English is the ability to speak, which is equal to $40 \%$. This shows that students know the needs of the job market, where almost all health companies place English language skills verbally and in writing as a requirement in hiring. In second place is followed by mastery of grammar by $30 \%$. Next is the ability to read by $20 \%$ and the last is the ability to write by $10 \%$. The conclusion that can be drawn from the two tables above is students assume the ability to speak or communicate is very important for their future steps. The percentage of the second question can be seen in the following picture:

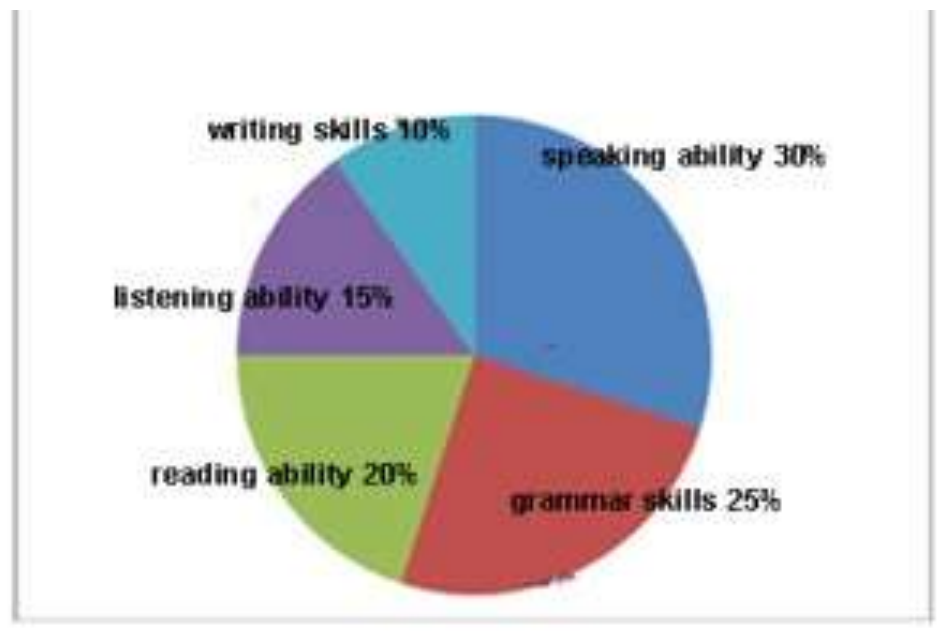

The next question about what topics or materials they want in the learning process in class. They consider all topics offered to be important to study because all topics are related and in accordance with health in the field of Pharmacy. This shows that they expect learning that is in line with the needs of their profession. Related to the topics they choose, of course the future implementation is the presentation of material that prioritizes their needs, namely being able to communicate well. Therefore understanding and using English language skills in meeting their professional needs is a goal that must be fulfilled. Details of the percentage can be seen as follows (Images 2): 


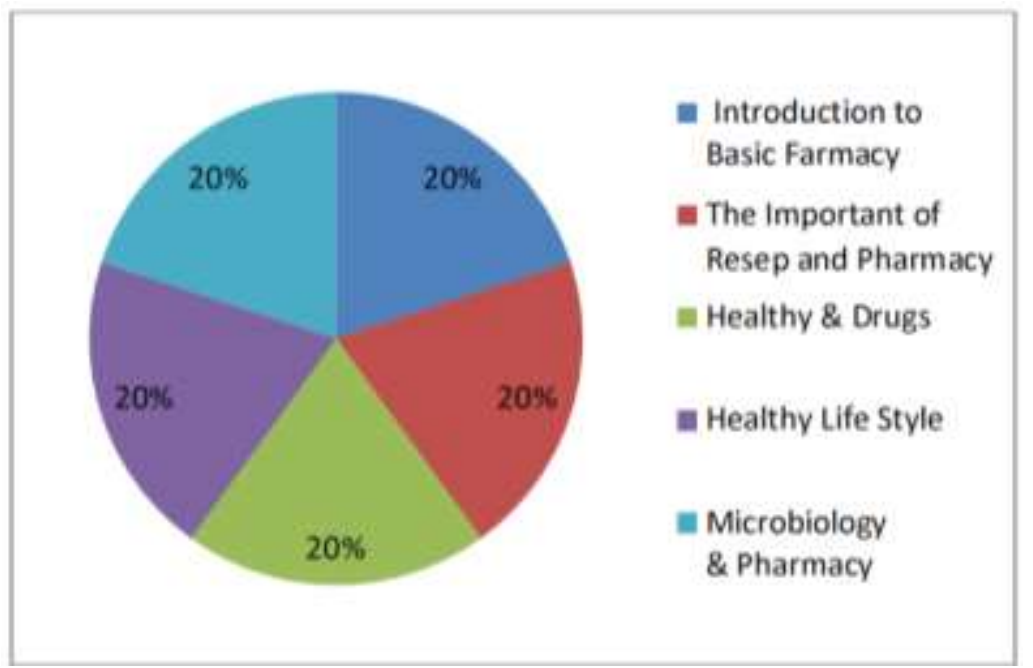

Figure 3. The desired topic in learning English about Health and Pharmacy

The last question is the use of media in the form of technology that can support their learning in the classroom (Images 4). The use of computer applications to improve English skills is the most preferred choice. This shows that students want learning that is supported by computer technology. Of course it is not enough just to apply technology, but it must be accompanied by an appropriate learning strategy that can improve students' abilities by utilizing technology. In this case the role of the teacher or lecturer is very important in order to arrange creative learning activities by utilizing the use of appropriate technology that is in accordance with student competencies. Details of the percentage can be seen as follows:

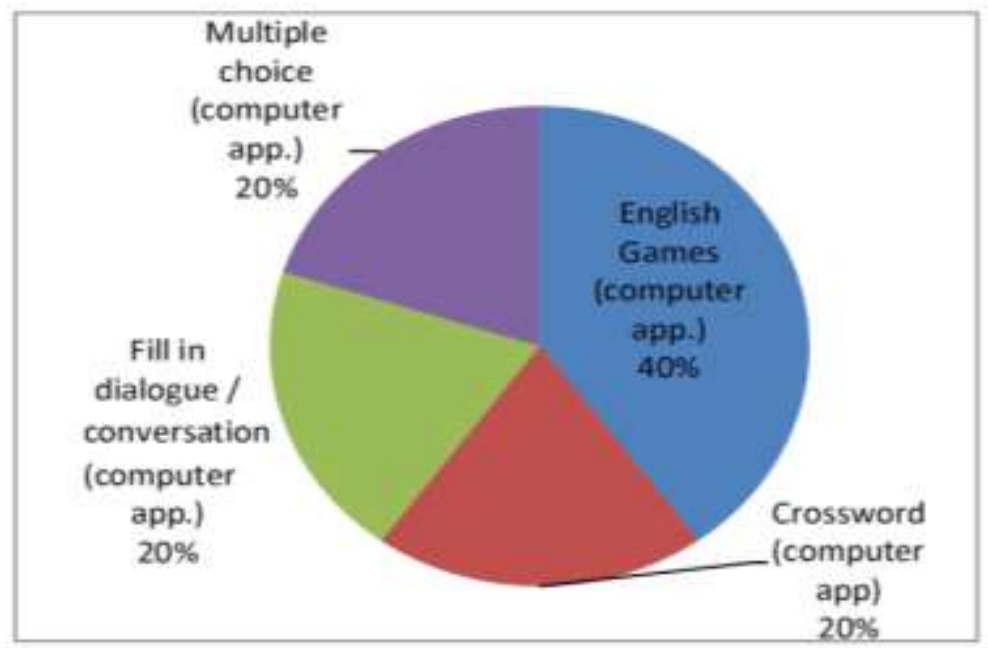

Figure 4. The use of technology in English courses

In the results of research and discussion related to the results of the questionnaire and the results of interviews with English lecturers who teach students of diploma three (D3) pharmacy department of Surabaya Pharmacy Academy follows. 


\subsection{Target Analysis}

Based on interviews with local English lecturers, the outcomes expected by academics in diploma three (D3) pharmacy department of Surabaya Pharmacy Academy are to make students of diploma three (D3) pharmacy departments into quality graduates who are able to compete in the world of work. To fulfill this goal, one of the obligations of academics is to equip graduates of diploma three (D3) pharmacy department of Surabaya Pharmacy Academy with adequate English language skills as a provision for the demands of their profession going forward. This is in line with the opinion (O'Neill and Palmer, 2004) which states that the institution is obliged to direct students to be able to fulfill their competencies in order to compete in the world of work. Entering the world of work, English language skills are needed when conducting communication or outreach in a company that involves colleagues who are accustomed to using English. In order to achieve intermediate level abilities and oriented towards preparing for the job market, it is better to study English in a class of diploma three (D3) courses in pharmacy to consider the needs of the job market.

In connection with the analysis of student targets in learning English, questionnaire data shows that the purpose of learning English for students in diploma is to be able to communicate using English actively. In other words, the ability to speak fluently and communicatively is very desirable in order to prepare themselves to fulfill the demands of their profession in the future. As opinion (Aysan, 2015, Agussani and Ansari, 2020) institutions need to consider the needs of students in accordance with their desires in order to increase motivation in learning and can meet their career needs. This proves that the desire of students who lead to improving speaking skills is already in accordance with the needs of the job market which requires the ability to communicate in English well.

\subsection{Analysis of learning needs}

In connection with the selection of material that is in accordance with the subject area of the student about the demand for English teaching materials that are in accordance with the subject area of the student, it is obtained data that all topics related to and in accordance with health in the pharmaceutical field they deem important to study. This is in line with the opinion (O'Neill and Palmer, 2004), namely the provision of English learning materials in accordance with the main subject of student studies will be very useful to prepare students for work competition. It can also increase students' motivation to learn English because the material provided is in accordance with what they want (Moussu and Llurda, 2008, Wats and Wats, 2009). Thus students are expected to be able to improve their English skills by fulfilling teaching materials that are in accordance with the basic competencies they need to have.

From the interview results it was obtained that innovative and interactive teaching of English is expected to deliver students the ability to use English both verbally and in written form. This is related to the use of technology obtained from the results of the questionnaire that students expect the use of technology in the form of computer applications that can support their learning in class. The purpose of digital or multimedia technology-based learning materials is to help students to achieve the best learning performance through effective instructional strategies applied in learning materials. This is consistent with what was stated (Medina et al., 2013), he stated that lecturers must be able to build good learning modules where students can obtain digital literacy, collaborative problem solving, creativity and many other skills, while interacting with innovative and interesting technology . In addition (Robles, 2012, Shahroom and Hussin, 2018) also assumes that technology can help facilitate innovation in the local context by bringing new ideas to educators, documenting and sharing applications related to schools and other professionals around the world. Therefore, teachers or vocational lecturers need to apply curriculum or teaching material that can be 
accessed by students by understanding concepts and subject matter with appropriate digital multimedia features. With the explanation above, it is hoped that it can inspire lecturers and teachers to integrate or apply appropriate technology into English vocational education courses.

\section{Conclusion}

Based on the results of the analysis obtained by researchers that the level of mastery of ESP in the analysis of student targets and needs. Students need the ability to speak fluently and competence in a foreign language to meet future professional demands. Thus, learning English in the students of diploma three (D3) Pharmacy departments of Surabaya Pharmacy Academy. Students and the future quality of student graduates must consider students' needs (necessities) in order to fulfill student competencies. Through the use of appropriate teaching methods and media in the classroom, lecturers can create an academic atmosphere conducive to learning for students studying ESP in the classroom, based on the students' needs, learning goals, and objectives that result in the expected and determined competencies.

\section{References}

Agussani, A. and K. Ansari. 2020. The Approach to Indonesian Language and Literature Curriculum in the Industrial Revolution Era 4.0 and Society 5.01. Kumpulan Penelitian dan Pengabdian Dosen.

Antony, J., W. K. Balzer, M. H. Brodke, and E. T. Kizhakethalackal. 2015. Lean higher education: successes, challenges, and realizing potential. International Journal of Quality \& Reliability Management.

Aysan, E. 2015. Learning science and science education in a new era. Ann Med Surg (Lond) $4(2): 158-161$.

Budiarta, I. K. and N. W. Krismayani. 2014. Improving speaking skill and developing character of the students through collaboration of think-pair-share and the concept of tri kaya parisudha. Jurnal Santiaji Pendidikan (JSP) 4(2):73-80.

Hermann, M., T. Pentek, and B. Otto. 2016. Design principles for industrie 4.0 scenarios. Pages 3928-3937 in Proc. 2016 49th Hawaii international conference on system sciences (HICSS). IEEE.

Lindsey, K. A., F. R. Manis, and C. E. Bailey. 2003. Prediction of first-grade reading in Spanish-speaking English-language learners. Journal of educational psychology 95(3):482.

Ma, J., S. Baum, M. Pender, and D. W. Bell. 2015. Trends in College Pricing, 2015. Trends in Higher Education Series. College Board.

Manis, F. R., K. A. Lindsey, and C. E. Bailey. 2004. Development of reading in grades K-2 in Spanish-speaking English-language learners. Learning Disabilities Research \& Practice 19(4):214-224.

Mayfield, M. 2011. Creating training and development programs: using the ADDIE method. Development and Learning in Organizations: An International Journal 25(3):19-22.

Medina, M. S., C. M. Plaza, C. D. Stowe, E. T. Robinson, G. DeLander, D. E. Beck, R. B. Melchert, R. B. Supernaw, V. F. Roche, and B. L. Gleason. 2013. Center for the Advancement of Pharmacy Education 2013 educational outcomes. American journal of pharmaceutical education 77(8).

Moussu, L. and E. Llurda. 2008. Non-native English-speaking English language teachers: History and research. Language teaching 41(3):315-348. 
O’Neill, M. A. and A. Palmer. 2004. Importance-performance analysis: a useful tool for directing continuous quality improvement in higher education. Quality assurance in education.

Ottolini, M. C., P. O. Ozuah, N. Mirza, and L. W. Greenberg. 2010. Student perceptions of effectiveness of the eight step preceptor (ESP) model in the ambulatory setting. Teach Learn Med 22(2):97-101.

Robles, M. M. 2012. Executive perceptions of the top 10 soft skills needed in today's workplace. Business communication quarterly 75(4):453-465.

Shahroom, A. A. and N. Hussin. 2018. Industrial revolution 4.0 and education. International Journal of Academic Research in Business and Social Sciences 8(9):314-319.

Soliman, N. A. 2014. Using e-learning to develop EFL students' language skills and activate their independent learning. Creative Education 2014.

Wats, M. and R. K. Wats. 2009. Developing Soft Skills in Students. International Journal of Learning 15(12). 